\title{
The effect of lung transplantation on the neural drive to the diaphragm in patients with severe COPD
}

\author{
H. Brath*, H. Lahrmann*, T. Wanke*, W. Wisser**, M. Wild*, \\ B. Schlechta**, H. Zwick*, W. Klepetko**, O.C. Burghuber ${ }^{+}$
}

The effect of lung transplantation on the neural drive to the diaphragm in patients with severe COPD. H. Brath, H. Lahrmann, T. Wanke, W. Wisser, M. Wild, B. Schlechta, H. Zwick, W. Klepetko, O.C. Burghuber. (CERS Journals Ltd 1997.

ABSTRACT: Little is known about the effects of lung transplantation (LT) on the neural drive to the diaphragm and on the endurance of respiratory muscles in patients with severe chronic obstructive pulmonary disease (COPD). The aim of this study was to evaluate these effects of single-lung (SLT) and double-lung transplantation (DLT).

The neural drive to the diaphragm was assessed during fatiguing inspiratory threshold loading manoeuvres in six SLT recipients, six DLT recipients and seven patients with severe COPD, by using diaphragmatic surface electromyograms. During threshold loading, the patients had to generate $80 \%$ of their maximal transdiaphragmatic pressure with each breath. The endurance of inspiratory muscles was defined as the time from the beginning of a resistive breathing trial until exhaustion $(t \mathrm{lim})$.

In DLT recipients and even in SLT recipients (on both sides), neural activation of the diaphragm was significantly lower than in COPD patients $(\mathbf{p}<0.05)$. However, no statistically significant difference in $t \mathrm{lim}$ was seen between LT recipients and COPD patients.

The data suggest that single-lung and double-lung transplantations cause a significant decrease of the neural drive to the diaphragm, while the endurance of inspiratory muscles is well-preserved in patients with advanced chronic obstructive pulmonary disease. This may contribute to reduced sensation of inspiratory effort during ventilatory stress, thus improving the quality of life.

Eur Respir J 1997; 10: 424-429.
*Pulmonary Department and "L. Boltzmann Forschungsstelle für Umweltpneumologie", Lainz Hospital, Vienna, Austria. **Second Department of Surgery, University of Vienna, Austria. +Dept of Internal Medicine, General Hospital Korneuburg, Austria.

Correspondence: H. Brath

Pulmonary Dept

Lainz Hospital

Wolkersbergenstr. 1

A-1130 Vienna

Austria

Keywords: Chronic obstructive pulmonary disease

diaphragmatic electromyogram

lung transplantation

Received: March 221996

Accepted after revision October 251996
Improved surgical techniques and effective immunosuppression have revolutionized solid organ transplantation, and lung transplantation has become a promising therapeutic option in patients with various end-stage lung diseases [1]. From the early 1980s, when the Toronto Lung Transplant Group started reporting successful lung transplantations [2], until now, the indications and the number of transplantations, as well as the knowledge of the effects of lung transplantation (LT) on the human physiology, have markedly increased. Although singlelung (SLT) and double-lung transplantation (DLT) clearly improve lung function [3], blood gas values [3] and right ventricular function [4], little is known about the effects of LT on inspiratory muscle function. In a recent study, we have shown that in patients with severe chronic obstructive pulmonary disease (COPD) LT improves diaphragmatic muscle strength by placing the diaphragm in a more favourable position for generating pressure [5]. However, the effects of LT on the neural activation pattern of the diaphragm and its effects on inspiratory muscle endurance are still unknown.

Therefore, the aim of this study was to evaluate the effects of LT on the neural drive to the diaphragm in patients with severe COPD during ventilatory stress induced by breathing against fatiguing threshold loads.
We also intended to determine the effects of LT on the endurance of inspiratory muscles by analysing the timespan from the beginning of the resistive breathing tests until exhaustion.

\section{Methods}

\section{Patients}

Twelve LT recipients (six SLT recipients ( 3 males and 3 females), and six DLT recipients (3 males and 3 females)), and seven patients with severe COPD prior to transplantation (4 males and 3 females) entered the study. Two SLT recipients (1 male and 1 female) and two DLT recipients ( 1 male and 1 female) were also studied preand postoperatively. All LT recipients had transplantation because of severe emphysema. One SLT recipient and one COPD patient had $\alpha_{1}$-antitrypsin deficiency emphysema. The lung function parameters of the COPD patients were similar to those of the LT recipients preoperatively. They were characterized by chronic airflow obstruction (forced expiratory volume in one second $(\mathrm{FEV} 1)<40 \%$ predicted, ratio of FEV1 to forced vital 
capacity (FVC) <0.5) and substantial pulmonary hyperinflation (functional residual capacity (FRC) $>130 \%$ pred).

All patients were clinically stable and had not had any acute respiratory exacerbation for at least 1 month preceding the study. Patients with coexisting diseases, such as left ventricular dysfunction, renal failure, neuromuscular diseases or alcoholism, were excluded. Five COPD patients and $6 \mathrm{LT}$ recipients prior to surgery were taking oral corticosteroids, with an average dose of $<$ $30 \mathrm{mg}$ prednisone $\cdot$ day $^{-1}$ during the last 3 months prior to the study or prior to surgery, respectively. No subject had taken oral corticosteroids for more than $5 \mathrm{yrs}$, and the average daily dose was $<12 \mathrm{mg}$ prednisone within that period. Postoperatively, all LT recipients were on immunosuppressive therapy, including corticosteroid $\left(0.2-0.3 \mathrm{mg} \cdot \mathrm{kg}^{-1}\right.$ prednisone daily), azathioprine (1-2 $\mathrm{mg} \cdot \mathrm{kg}^{-1}$ daily) and cyclosporin (plasma levels of 300$400 \mathrm{ng} \cdot \mathrm{L}^{-1}$ ). There was no appreciable difference in medication between SLT and DLT recipients. The LT recipients were studied 1-3 months after transplantation. All patients participating in the study had given their informed consent. The study was approved by the Human Subject Committee of the hospital.

\section{Data acquisition}

Lung function tests included spirometry and whole body plethysmography. For spirometry, an open system was used with integration of the flow signal. For whole body plethysmography, the constant volume method was used (Jaeger, Würzburg, Germany). The predicted normal values of QUANJER et al. [6] were used.

The recording of diaphragmatic electromyographic activity (EMGdi) has been described in detail previously [7]. In brief, surface electrodes were applied on the lower right side, and in SLT recipients also on the left side of the anterolateral rib cage, to record the EMGdi of the respective hemidiaphragms. The muscle action potentials were amplified (Neurostar; Medelec, Surrey, UK) and filtered (roll-off $=40 \mathrm{db} \cdot$ decade $^{-1}$ at a cut-off frequency of $500 \mathrm{~Hz}$ ) to avoid any aliasing effect. The inspiratory oesophageal pressure $\left(P_{\mathrm{oes}}\right)$ curve was taken as the trigger signal for data acquisition, with the pretrigger being $200 \mathrm{~ms}$. The two EMG channels and the $P$ oes curve were sampled on-line to the hard disk of a PC workstation, by using a sampling rate of $2 \mathrm{kHz} \cdot$ chan- $^{-}$ nel $^{-1}$ and a 12-bit digital resolution.

Oesophageal and gastric pressures were measured using a flexible, double-lumen, water-perfused catheter system, as described previously [8]. The proximal ends of the catheter were connected to a pressure transducer (P23ID; Gould-Statham, Cleveland, OH, USA). Transdiaphragmatic pressure $(P \mathrm{di})$ was calculated by subtracting oesophageal pressure from gastric pressure $(\mathrm{Pga})$.

\section{Study design}

Initially, the water-perfused catheter was passed through one nostril, with its gastric distal orifice being set at the stomach and its oesophageal orifice at the middle third of the oesophagus [9]. After positioning, the catheter was fixed at the nostril. Each patient then performed maximal sniff manoeuvres at resting end-expiration. The patient was asked to take short sharp sniffs through the nose as hard as possible, without noseclip, and with the mouth closed. The highest pressure value out of 10 sniffs was selected for analysis $(P$ di,max $)$. There was an interval of 30-45 s between each sniff trial.

During the threshold loading tests, the subjects breathed against a variable inspiratory threshold load as described by NicKeRson and KeEns [10]. To start inspiration, the subjects had to lift a movable weighted plunger guided in a metallic cylinder. This weight was adjusted in such a way that the patients had to generate $80 \%$ of their respective $P$ di,max during each inspiration throughout the whole trial. During the threshold loading runs, the patients were not instructed how to generate their $P$ di; they were free to choose their own pattern of inspiratory muscle activation. Since the ratio of $P$ di $/ P$ di,max was the same in SLT and DLT recipients and in the COPD patients, the mechanical loads within these groups were amenable to comparison. The $P$ oes and $P$ ga swings were monitored continuously on a 4-channel paper recorder (Beckmann 511A, Fullerton, CA, USA). $P$ oes and $P$ ga were sampled to a personal computer (PC-486/66), and $P$ di was calculated and displayed on-line on a video screen to provide a visual feedback for the patient. During the trial, the subjects were given sound signals in order to breathe at a constant frequency of 25 breaths $\cdot \mathrm{min}^{-1}$ and to keep the ratio between in-spiratory time $(t \mathrm{I})$ and expiratory time $(t \mathrm{E})$ constant at $1: 2$ ratio $(t \mathrm{I}=0.8 \mathrm{~s}, t \mathrm{E}=1.6 \mathrm{~s})$. The analysis of the expired fraction of carbon dioxide $\left(F\right.$ ET, $\left.\mathrm{CO}_{2}\right)$ was performed by means of an infra-red $\mathrm{CO}_{2}$ analyser (Jaeger); sampling was carried out at the expiratory outlet of a two-way valve, which allowed unloaded expiration. To avoid hypocapnia, $\mathrm{CO}_{2}$ was added to the inspiratory flow, if necessary. In addition, oxygen-dependent COPD patients received their usual dose of oxygen, so that all subjects had an arterial oxygen tension $\left(\mathrm{Pa}, \mathrm{O}_{2}\right)$ of $8.0-10.6 \mathrm{kPa}(60-80 \mathrm{mmHg})$.

Every minute, the patients were asked to grade their effort sensation by showing a number on a scale from 1 (easiest effort) to 10 (hardest effort), according to a modified Borg scale. The resistive breathing runs were stopped when the patient could not tolerate the effort any longer or was unable to achieve and sustain the predetermined $80 \%$ of $P$ di,max for at least three consecutive breaths. The Borg rating was used as a subjective exhaustion parameter; the decrease of centroid frequency served as the parameter for objective exhaustion [11]. The period from the beginning to the end of the runs was defined as endurance time $(t \mathrm{lim})$.

\section{Data analysis}

The influence of electrocardiac (ECG) signals on EMG data was minimized by a subtraction algorithm, which left the amplitude and the frequency content of the EMG unaltered [12]. Centroid frequency was used to quantify the leftward shift of the EMG power spectrum, which occurs during the development of muscle fatigue, and thus represents an early sign thereof [11]. Centroid frequency was evaluated near the end $(90 \%)$ of $t \mathrm{lim}$; and was averaged from five consecutive breaths to minimize the influence of breath-to-breath fluctuation. Root mean square (RMS) served as an estimater of the neural phrenic drive to both hemidiaphragms. Since the amplitude of EMGdi, 
as quantified by RMS, indicates the phrenic in-put to the diaphragm, it can be used as a valid index of diaphragmatic neural activation [13-15]. It represents a statistically valid measure of the amplitude behaviour of the EMG, and thus describes the level of global muscle fibre excitation. Furthermore, it is characterized by a very good signal resolution [16].

To minimize the intersubject variability of the EMG parameters (effects of electrode configuration, tissue filtering, temperature, etc.) centroid frequency and RMS were normalized to the average values recorded during the first three loaded breaths. A third order polynomial function was used in order to describe RMS time series. From this function, the RMS values were calculated at 10,50 and $90 \%$ of $t \mathrm{lim}$.

To assess the relative contribution of the diaphragm and the intercostal/accessory muscles to the respiratory output during the breathing tests, the ratio $P_{\text {oes}} / P_{\text {di }}$ was calculated near the beginning (at $10 \%$ ) of $t \mathrm{lim}$, in the middle (at 50\%), and before the end (at 90\%) of $t \mathrm{lim}$. All software used was developed in ASYST (ASYST Software Technologies Inc., Rochester, NY, USA).

\section{Statistical analysis}

The data obtained from COPD patients and LT recipients were compared by means of the nonparametric Wilcoxon test for unpaired samples. A p-value of less than 0.05 was considered statistically significant. All data are presented as mean values (SD).

Table 1. - Physical characteristics of single-lung transplant (SLT) and double-lung transplant (DLT) recipients and of patients with chronic obstructive pulmonary disease (COPD)

\begin{tabular}{lcrrr}
\hline & $\begin{array}{c}\text { SLT } \\
\text { recipients } \\
(\mathrm{n}=6)\end{array}$ & $\begin{array}{c}\text { DLT } \\
\text { recipients } \\
(\mathrm{n}=6)\end{array}$ & $\begin{array}{r}\text { COPD } \\
\text { patients } \\
(\mathrm{n}=7)\end{array}$ & p-value \\
\hline Age yrs & $54(8)$ & $50(8)$ & $56(7)$ & NS \\
Height cm & $170(11)$ & $173(11)$ & $170(12)$ & NS \\
Weight kg & $66(11)$ & $69(12)$ & $67(10)$ & NS \\
BMI $\mathrm{kg} \cdot \mathrm{m}^{-2}$ & $22.8(1.8)$ & $23.1(2.1)$ & $23.2(1.9)$ & NS \\
\hline
\end{tabular}

Values are presented as mean, and SD in parenthesis. BMI: body mass index; NS: not significant.

\section{Results}

There were no significant differences in the anthropometric data between SLT and DLT recipients on the one hand and COPD patients on the other (table 1). Their pulmonary function parameters are presented in table 2 . There was no statistically significant difference in pulmonary function data and the blood gas values between SLT and DLT recipients preoperatively, and between both of these groups prior to surgery and the COPD patients. Postoperatively, all transplant recipients showed significant improvements of their lung functions and arterial blood gas values.

\section{Neural drive to the diaphragm and inspiratory muscle endurance in DLT recipients}

Comparison revealed that in DLT recipients the RMS calculated as percentage of the average RMS values, which were recorded during the first three loaded breaths (RMS/RMS0), evaluated at 10, 50 and $90 \%$ of $t \mathrm{lim}$, was significantly lower than in COPD patients $(\mathrm{p}<0.05)$ (fig. 1 ). Thus, the neural drive to the diaphragm, which, in this special experimental situation was represented by RMS, proved to be lower. Although the endurance time of DLT recipients was longer than that of SLT recipients and COPD patients, the difference was not statistically significant (table 3 ). The two DLT recipients, assessed pre- and postoperatively, showed the same trend with respect to the neural diaphragmatic activation pattern (fig. 1) and inspiratory muscle endurance (table 3 ).

\section{Neural drive to the diaphragm and inspiratory muscle endurance in SLT recipients}

SLT recipients showed on the transplanted and the nontransplanted sides significantly lower RMS/RMS0 ratios at 10,50 and $90 \%$ of $t \mathrm{lim}$, in comparison with COPD patients $(\mathrm{p}<0.05)$ (fig. 1$)$. At these points of $t \mathrm{lim}$, SLT recipients and DLT recipients exhibited no significant difference in their RMS/RMS0 ratios, nor was there a statistically significant difference between the transplanted and the nontransplanted sides in SLT recipients. The endurance time in SLT recipients was seen to be longer than that in COPD patients and shorter than in DLT recipients, but neither difference reached statistical

Table 2. - Lung function parameters and blood gas values in lung transplant (LT) recipients pre- and postoperatively and in patients with chronic obstructive pulmonary disease (COPD)

\begin{tabular}{|c|c|c|c|c|c|}
\hline & $\begin{array}{c}\text { LT recipients } \\
(\mathrm{SLT}+\mathrm{DLT} \text { preoperatively }) \\
(\mathrm{n}=12)\end{array}$ & $\begin{array}{l}\text { SLT recipients } \\
\text { (postoperatively) } \\
(\mathrm{n}=6)\end{array}$ & $\begin{array}{l}\text { DLT recipients } \\
\text { (postoperatively) } \\
(\mathrm{n}=6)\end{array}$ & & $\begin{array}{l}\text { OPD } \\
\text { itients } \\
n=7)\end{array}$ \\
\hline IVC $\%$ pred & $55 \quad(12)$ & $66 \quad(9)$ & 72 (12) & 58 & (11) \\
\hline FEV1 $\%$ pred & 26 (9) & 55 (14) & 63 (15) & 30 & (9) \\
\hline TLC \% pred & $127 \quad(16)$ & 106 (4) & $90 \quad(18)$ & 131 & (18) \\
\hline FRC \%pred & $222 \quad(21)$ & 131 (10) & 119 (10) & 218 & (24) \\
\hline $\mathrm{RV} \%$ pred & $298 \quad(39)$ & $212 \quad(24)$ & $147 \quad(20)$ & 306 & (39) \\
\hline$R$ aw $\mathrm{kPa} \cdot \mathrm{L} \cdot \mathrm{s}^{-1}$ & $0.76 \quad(0.24)$ & $0.22(0.06)$ & $0.13 \quad(0.05)$ & 0.72 & $(0.26)$ \\
\hline$P \mathrm{a}, \mathrm{O}_{2} \quad \mathrm{kPa}$ & 8.3 (1.4) & $11.2(1.2)$ & 11.9 (1.4) & 8.1 & (1.3) \\
\hline$P \mathrm{a}, \mathrm{CO}_{2} \quad \mathrm{kPa}$ & $5.7 \quad(1.2)$ & $4.7 \quad(0.8)$ & $4.8 \quad(0.8)$ & 5.8 & $(1.0)$ \\
\hline
\end{tabular}

Values are presented as mean, and SD in parenthesis. SLT: single-lung transplant recipients; DLT: double-lung transplant recipients; IVC: inspiratory vital capacity; FEV1: forced expiratory volume in one second; TLC: total lung capacity; FRC: functional residual capacity; RV: residual volume; $R$ aw: airway resistance; $P \mathrm{a}, \mathrm{O}_{2}$ and $P$ a, $\mathrm{CO}_{2}$ : arterial oxygen and carbon dioxide tension, respectively; \% pred: percentage of predicted value. Sources of predicted values are given in the text. 


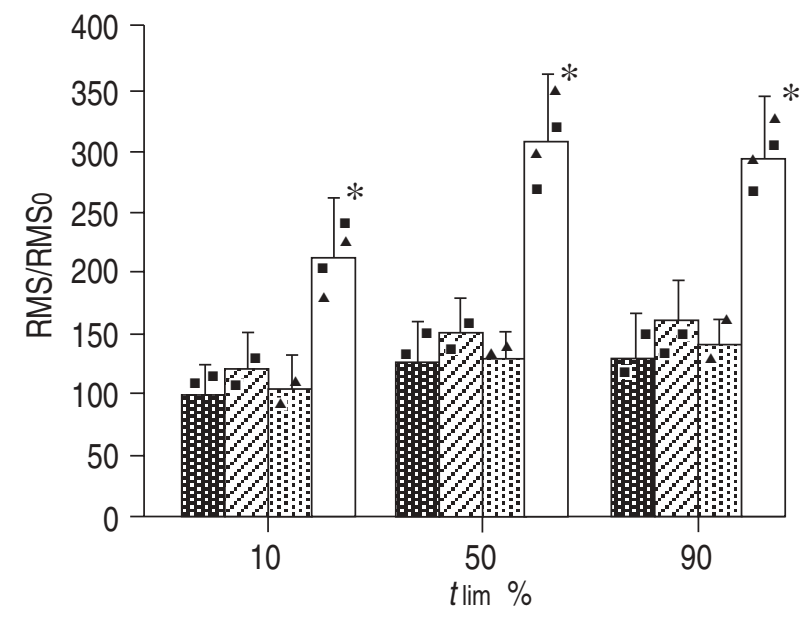

Fig. 1. - Neural activation of the diaphragm throughout the loaded breathing runs. Values in DLT recipients and COPD patients are taken from their right hemidiaphragms. All values are presented as group means and SD. *: $\mathrm{p}<0.05$, significant difference to the SLT (on the transplanted and nontransplanted sides) and DLT recipients postoperatively. $\mathrm{x}$-axis: time normalized to total endurance time $(t \lim )$. $\mathrm{y}-$ axis: root mean square (RMS) normalized to the mean of the first three loaded breaths (RMSO). SLT: single-lung transplant recipients; DLT: double-lung transplant recipients; COPD: chronic obstructive pulmonary disease. operated side); $:$ : DLT; $\square$ : COPD. $\square$ : values of the two SLT recipients measured pre- and postoperatively; $\Delta$ : values of the two DLT recipients, measured pre- and postoperatively.

significance (table 3). The two SLT recipients, assessed pre- and postoperatively, exhibited the same trend with respect to the neural diaphragmatic activation pattern (fig. 1) and inspiratory muscle endurance (table 3).

\section{Exhaustion parameters}

In all subjects, the respective centroid frequency was seen to have decreased to $80 \%$ or less at the end of the loaded test, compared to the average values recorded during the first three loaded breaths. SLT recipients: 76 (5)\% (74 (6)\% on the transplanted, and $78(4) \%$ on the nontransplanted side); DLT recipients 75 (5)\%; and COPD patients 77 (4)\%. No difference was found in the Borg ratings of the subjects at the time of termination. The average values reported by SLT recipients, DLT recipients and COPD patients were 8.2 (2.3), 7.6 (2.8) and 8.0 (1.9), respectively.
Global inspiratory and diaphragmatic muscle strength

In SLT and DLT recipients, the $P$ di and $P$ oes values observed were higher than those in the COPD patients, reaching statistical significance only in the DLT recipients $(\mathrm{p}<0.05)($ table 3$)$. There was no statistically significant difference between SLT and DLT recipients.

\section{$P_{\mathrm{oes}} / P_{\mathrm{di}}$ behaviour during resistive breathing runs}

The relative contributions of the diaphragm and intercostal/accessory muscles to the respiratory output, calculated as the ratio $P_{\mathrm{oes}} / P_{\text {di near }}$ the beginning (at $10 \%$ ), in the middle (at 50\%) and before the end (at 90\%) of total endurance time $(t \mathrm{lim})$ are presented in table 4 . There were no statistically significant differences in the $P$ oes/ $P$ di ratios between the SLT recipients, DLT recipients and COPD patients, although COPD patients tended to have higher $P_{\mathrm{oes}} / P$ di than $\mathrm{LT}$ recipients. With increasing percentage of $t \mathrm{lim}, P$ ga decreased (table 4$)$. At $10 \%$ of $t \mathrm{lim}$, two SLT recipients and two COPD patients showed negative $P$ ga; at $50 \%$ of $t \mathrm{lim}$, one DLT recipient and one COPD patient additionally showed negative $P$ ga; and at $90 \%$ of $t \mathrm{lim}$ there were three SLT, two DLT recipients and four COPD patients with negative $P$ ga values. No patient showed any appreciable change in $P$ ga or $P$ oes at end-expiration during a fatiguing run, which indicated that end-expiratory lung volume remained constant throughout the test.

Table 4. $-P_{\mathrm{oes}} / P_{\text {di }}$ ratio as index for the contribution of $P_{\mathrm{oes}}$ and $P_{\mathrm{ga}}$ to $P_{\mathrm{di}}$ at 10,50 and $90 \%$ total endurance time $(t \mathrm{lim})$ in single-lung transplant $(\mathrm{SLT})$ and doublelung transplant (DLT) recipients postoperatively and in patients with chronic obstructive pulmonary disease (COPD)

\begin{tabular}{lccc}
\hline & $\begin{array}{c}\text { SLT } \\
\text { recipients } \\
(\mathrm{n}=6)\end{array}$ & $\begin{array}{c}\text { DLT } \\
\text { recipients } \\
(\mathrm{n}=6)\end{array}$ & $\begin{array}{c}\text { COPD } \\
\text { patients } \\
(\mathrm{n}=7)\end{array}$ \\
\hline$P_{\mathrm{oes}} / P_{\mathrm{di}}$ at $10 \% t \mathrm{lim}$ & $0.87(0.21)$ & $0.88(0.13)$ & $0.98(0.11)$ \\
$P_{\mathrm{oes}} / P_{\mathrm{di}}$ at $50 \% t \mathrm{lim}$ & $0.86(0.22)$ & $1.00(0.22)$ & $1.03(0.16)$ \\
$P_{\mathrm{oes}} / P_{\mathrm{di}}$ at $90 \% t \mathrm{lim}$ & $0.92(0.31)$ & $1.04(0.24)$ & $1.11(0.24)$
\end{tabular}

Values are presented as mean, and SD in parenthesis. $P_{\text {oes: }}$ oesophageal pressure; $P$ ga: gastric pressure; $P$ di: transdiaphragmatic pressure.

Table 3. - Diaphragmatic and global inspiratory muscle function parameters of single-lung transplant (SLT) and double-lung transplant (DLT) recipients postoperatively and of patients with chronic obstructive pulmonary disease (COPD)

\begin{tabular}{|c|c|c|c|}
\hline & $\begin{array}{c}\text { SLT } \\
\text { recipients } \\
(\mathrm{n}=6)\end{array}$ & $\begin{array}{c}\text { DLT } \\
\text { recipients } \\
(\mathrm{n}=6)\end{array}$ & $\begin{array}{l}\text { COPD } \\
\text { patients } \\
(\mathrm{n}=7)\end{array}$ \\
\hline$t \lim \min$ & $\begin{array}{l}6.8(2.9) \\
{[7.6 ; 6.2]}\end{array}$ & $\begin{array}{l}9.3(7.0) \\
\{4.3 ; 9.0\}\end{array}$ & $\begin{array}{c}6.6(3.2) \\
{[7.0 ; 5.8],\{3.6 ; 6.5\}}\end{array}$ \\
\hline$P_{\text {oes, }}$ max $\mathrm{cmH}_{2} \mathrm{O}$ & $\begin{array}{c}67.7(21.5) \\
{[75,73]}\end{array}$ & $\begin{array}{c}76.7(11.0)^{*} \\
\quad\{73,85\}\end{array}$ & $\begin{array}{c}60.3(10.6) \\
{[70 ; 55],\{65,65\}}\end{array}$ \\
\hline$P$ di,max $\mathrm{cmH}_{2} \mathrm{O}$ & $\begin{array}{c}84.5(20.5) \\
{[85,97]}\end{array}$ & $\begin{array}{l}99.7(23.5)^{*} \\
\{100,118\}\end{array}$ & $\begin{array}{c}69.3(12.3) \\
{[77,73],\{75,83\}}\end{array}$ \\
\hline
\end{tabular}

Values are presented as mean, and SD in parenthesis. $t$ lim: total endurance time; $P$ oes,max: maximal oesophageal pressure; $P$ di,max: maximal transdiaphragmatic pressure; *: $\mathrm{p}<0.05$, when compared with COPD patients; $[\mathrm{x}]$ : values of the two SLT recipients, measured pre- and postoperatively; $\{\mathrm{x}\}$ : values of the two DLT recipients, measured pre- and postoperatively. 


\section{Discussion}

The results presented above showed a significantly lower neural drive to the diaphragm in severe COPD during ventilatory stress induced by fatiguing inspiratory threshold loading after DLT and SLT (both on transplanted and nontransplanted sides) in comparison with COPD patients with lung functions similar to those of LT recipients prior to surgery. In addition, DLT recipients showed significantly better global inspiratory and diaphragmatic muscle strength, in comparison with the same COPD patients. Furthermore, the results showed that the total endurance time $(t \mathrm{lim})$ (as defined previously) was not statistically significantly different between the LT recipients and the COPD patients. Thus, the endurance of the inspiratory muscles appears to be well-preserved even in end-stage COPD patients.

However, some circumstances might have influenced these results. For example, the patients were allowed to choose their own breathing pattern during the tests. A different recruitment pattern of the inspiratory muscles during these tests could have reduced the amplitude of EMGdi in the LT recipients by a comparatively higher recruitment of nondiaphragmatic inspiratory muscles. The analysis of the ratio of $P$ oes to $P$ di at comparable percentages of $t \mathrm{lim}$, revealed that there was no difference between COPD patients and LT recipients with respect to the pattern of inspiratory muscle recruitment. LT recipients even showed a trend, although not statistically significant, towards a lower $P_{\text {oes }} / P$ di ratio (table 4 ), and therefore a higher recruitment of the diaphragm. Thus, in the present study, it is unlikely that differences in inspiratory muscle recruitment resulted in a reduction of EMGdi.

Furthermore, the lungs of the COPD patients could have become more hyperinflated during the resistive breathing tests, which could have caused a spuriously reduced neuromechanical efficiency by placing the diaphragm in a less favourable position. In addition, the EMGdi activity per se may also have been influenced by changes in lung volume [17]. Analysing the gastric and oesophageal end-expiratory pressures, we found no appreciable change in the course of a fatiguing run in any of the three patient groups. Thus, we conclude that pulmonary hyperinflation did not occur during the tests.

Since we intended to analyse the SLT recipients' neural drive to both hemidiaphragms separately, we used surface EMG electrodes, and not oesophageal electrodes, which integrate the EMG signal from both hemispheres. Among others, SHARP and co-workers [18] have pointed out the limited use of surface electrodes to detect a leftward shift of the EMG power spectrum because of the low-pass filtering effect of the chest wall tissues. However, we found a significant decrease in centroid frequency in all of our patients, which demonstrated the validity of these data. The normalization of centroid frequency and RMS to the average values recorded during the first three loaded breaths probably enhanced the reliability of the method by reducing the intersubject variability. Moreover, such normalization minimizes intraindividual variability. To minimize interference from other muscles, all patients were seated in an individually adjusted chair with appropriate support for their backs and arms. Additionally, the subjects were instructed not to move and to sit as relaxed as possible during the loaded breathing runs. Using RMS as an estimater of muscle activation further reduces the effect of muscle cross-talk. Even if EMG activity of lower intercostal muscles and the diaphragm were in a ratio of $1: 2$, lower intercostals would still contribute only $11 \%$ to the resulting RMS value of the combined signal [16].

It might be argued that the LT recipients were not sufficiently exhausted at the end of $t \mathrm{lim}$. But since all subjects reported high values on the Borg scale, they were subjectively exhausted. As mentioned above, all of the patients additionally showed a decrease in centroid frequency to at least $80 \%$ of the respective basic value, which indicated diaphragmatic fatigue [19]. Furthermore, the relative contribution of $P$ ga to $P$ di decreased in the course of the resistive breathing runs, which implied that the subjects had to recruit additional inspiratory muscles to delay the onset of inspiratory muscle fatigue.

It was only possible to assess four out of $12 \mathrm{LT}$ recipients (two SLT and two DLT) pre- and postoperatively, so that these data were not used for further statistical analysis. These individual readings, however, were very much in line with the general trend presented above (fig. 1 and table 3 ).

In this study, a similar endurance time was found during the loaded breathing runs (with the same $80 \%$ of individual $P$ di,max being used as target pressure in each subject) in LT recipients and COPD patients (table 3), which indicates that the endurance capacity of the inspiratory muscles is well-preserved even in patients with severe COPD; despite the fact that LT improves lung function parameters and blood gas values significantly. Possibly, a larger number of subjects (reducing the high SD caused by big interindividual variations) or testing the same patients before and after LT (allowing a paired statistical test) would have resulted in a significant difference in $t \mathrm{lim}$, between DLT recipients and COPD patients. On the other hand, shortened muscles fatigue less easily than longer ones [20]. Animal studies have demonstrated that emphysema does not affect the fatigue resistance of the diaphragm [21]. In addition, AMEREDES and Clanton [22] have failed to demonstrate any effect of moderate hypoxia or hyperoxia on sustainable inspiratory pressure development.

Even though the present study revealed that inspiratory muscle endurance in COPD patients, determined by $t \mathrm{lim}$, was not significantly different from that in LT recipients, the results clearly demonstrated that diaphragmatic neural activation was significantly lower on the transplanted and nontransplanted sides of the SLT recipients and in the DLT recipients, as compared with the COPD patients. The higher level of neural drive to the diaphragm in COPD patients, as compared with transplant recipients during standardized resistive breathing tests, is most likely to be due to the intrinsic force-length properties of the diaphragm.

Several animal and human studies have shown that the efferent drive to the diaphragm is very well adjusted to account for changes in diaphragmatic mechanical efficiency [23-26]. The conditions that lead to an increased diaphragmatic operating length (the diaphragm is placed in a mechanically more advantageous position) are associated with a reduced neural activation of 
the diaphragm $[24,26]$. Only if the diaphragm is stretched beyond its optimal length, or is shortened and is, therefore, placed in a mechanically less favourable position, is its electrical activity increased. In COPD the diaphragm becomes shorter and flatter because of lung hyperinflation, causing it to contract from a fibre length that is shorter than normal and, therefore, more unfavourable. Furthermore, diaphragmatic flattening increases the radius of its curvature and, according to Laplace's law, the tension developed in the contracting diaphragm is poorly converted into transdiaphragmatic pressure in this state. By reducing the lung volume, lung transplantation puts the diaphragm in a better position for generating inspiratory pressure.

It is remarkable that the present study has shown that SLT induces a lower diaphragmatic neural activation even on the nontransplanted side. Evidently, the diaphragm of the transplanted side can take over some of the work of the nontransplanted one. This is especially interesting with regard to the discussion about the effectiveness of SLT, a form of transplantation which makes it possible to treat twice as many patients and, in most cases, cardiopulmonary bypass can be avoided [27].

There are two major aims in the treatment of patients with severe chronic obstructive pulmonary disease: firstly, to prolong life; and, secondly, to improve quality of life. With application of the right indication criteria, lung transplant is known to achieve, at least, the latter. A decreased neural activation of the diaphragm may contribute to the sensation of reduced inspiratory effort during ventilatory stress in activities of everydaylife, and may, thus, allow an improvement in the quality of life.

\section{References}

1. Grimm M, Wisser W, End A, et al. Early experience with sequential bilateral lung transplantation. J Thorac Cardiovasc Surg 1993; 106: 463-465.

2. The Toronto Lung Transplant Group. Unilateral lung transplantation for pulmonary fibrosis. $N$ Engl $J$ Med 1986; 314: 1140-1145.

3. Cooper JD, Patterson GA, Grossmann R, Maurer J, The Toronto Lung Transplant Group. Double-lung transplant for advanced chronic obstructive lung disease. Am Rev Respir Dis 1989; 139: 303-307.

4. Globits S, Burghuber OC, Koller J, et al. Effect of lung transplantation on right and left ventricular volumes and function measured by magnetic resonance imaging. Am J Respir Crit Care Med 1994; 149: 1000-1004.

5. Wanke T, Merkle M, Formanek D, et al. Effect of lung transplantation on diaphragmatic function in patients with chronic obstructive pulmonary disease. Thorax 1994; 49: 459-464.

6. Quanjer, PhH, Tammelin GJ, Cotes JE, Pedersen OF, Peslin R, Yernault J-C. Lung volumes and forced ventilatory flows. Report Working Party "Standardization of Lung Function Tests". European Coal and Steel Community. Eur Respir J 1993; 6(Suppl. 16): 5-40.

7. Wanke T, Lahrmann H, Formanek D, Zwick B, Merkle $\mathrm{M}$, Zwick $\mathrm{H}$. The effect of opioids on inspiratory muscle fatigue during inspiratory resistive loading. Clin Physiol 1993; 13: 349-360.

8. Wanke T, Schenz G, Zwick H, Popp W, Ritschka L, Flicker M. Dependence of maximal sniff-generated mouth and transdiaphragmatic pressures on lung volume. Thorax 1990; 45: 352-355.

9. Cotes JE. Assessment of mechanical and bellows attributes of the lung. In: Cotes JE, ed. Lung Function, Assessment and Application in Medicine. London, Blackwell Scientific Publications, 1979; pp. 208-210.

10. Nickerson BG, Keens TG. Measuring ventilatory muscle endurance in humans as sustainable inspiratory pressure. J Appl Physiol: Respirat Environ Exercise Physiol 1982; 52: 768-772.

11. DeLuca CJ. Myoelectric manifestation of localized muscular fatigue in humans. CRC Crit Rev Biomed Eng 1986; 11: 251-279.

12. Lahrmann H, Wanke T, Zwick H. A digital method of ECG artefact minimization in inspiratory muscle EMG. Eur Respir J 1990; 3: 187s.

13. Druz WS, Sharp JT. Activity of respiratory muscles in upright and recumbent humans. J Appl Physiol: Respirat Environ Exercise Physiol 1981; 51: 1552-1561.

14. Ginzburg AS, Lopata M, Önal E. Effects of loading and unloading the respiratory system on respiratory control and muscle function. Respiration 1989; 55: 16-27.

15. Sharp JT, Druz WS, Kondragunta VR. Diaphragmatic responses to body position changes in obese patients with obstructive sleep apnea. Am Rev Respir Dis 1986; 133: 32-37.

16. O'Brien MJ, van Eykern LA, Prechtl HFR. Monitoring respiratory activity in infants: a nonintrusive diaphragm EMG technique. In: Rolfe P, ed. Noninvasive Measurements, Vol. 2. London, Academic Press Inc., 1983; pp.132-177.

17. Gandevia SC, McKenzie DK. Human diaphragmatic EMG: changes with lung volume and posture during supramaximal phrenic stimulation. J Appl Physiol 1986; 60(4): 1420-1428.

18. Sharp JT, Hammond MD, Aranda AU, Rocha RD. Comparison of diaphragm EMG centroid frequencies: esophageal versus chest surface leads. Am Rev Respir Dis 1993; 147: 764-767.

19. Gross D, Grassino A, Ross WRD, Macklem PT. Electromyogram pattern of diaphragmatic fatigue. J Appl Physiol: Respirat Environ Exercise Physiol 1979; 46(1): 1-7.

20. Grassino AE, Clanton T. Mechanisms of muscle fatigue. Monaldi Arch Chest Dis 1993; 48(1): 94-98.

21. Farkas GA, Roussos C. Adaptability of the hamster diaphragm to exercise and/or emphysema. J Appl Physiol: Respirat Environ Exercise Physiol 1982; 53: 1263-1272.

22. Ameredes BT, Clanton TL. Hyperoxia and moderate hypoxia fail to affect inspiratory muscle fatigue in humans. J Appl Physiol 1989; 66(2): 894-900.

23. Banzett RB, Inbar GF, Brown R, Goldman M, Rossier A, Mead J. Diaphragm electrical activity during negative lower torso pressure in quadriplegic man. J Appl Physiol: Respirat Environ Exercise Physiol 1981; 51: 654-659.

24. Cheeseman M, Revelette WR. Phrenic afferent contribution to reflexes elicited by changes in diaphragm length. J Appl Physiol: Respirat Environ Exercise Physiol 1990; 51: 640-647.

25. Green M, Mead J, Sears TA. Muscle activity during chest wall restriction and positive pressure breathing in man. Respir Physiol 1978; 35: 283-300.

26. Reid MB, Banzett RB, Feldman HA, Mead J. Reflex compensation of spontaneous breathing when immersion changes diaphragm length. J Appl Physiol 1985; 58: $1136-1142$.

27. Briffa NP, Dennis C, Higenbottam T, et al. Single-lung transplantation for end-stage emphysema. Thorax 1995; 50: $562-564$. 